\title{
Evaluasi Termal Vertical Greenery System Tipe Green Facade pada Dinding Bangunan
}

\section{Thermal Evaluation of Vertical Greenery System Type Façade on Building Wall}

\author{
Muhammad Haviz $^{1} \bowtie$, Muhammad Taufik Toha ${ }^{2}$, Riman Sipahutar ${ }^{3}$, Oki Alfernando ${ }^{4}$ \\ ${ }^{1}$ Jurusan Teknik Kimia, Fakultas Teknik, Universitas Lampung \\ ${ }^{2} J u r u s a n$ Teknik Pertambangan, Fakultas Teknik, Universitas Sriwijaya \\ ${ }_{3}^{3}$ Jurusan Teknik Mesin, Fakultas Teknik, Universitas Sriwijaya \\ ${ }^{4}$ Program Studi Teknik Kimia, Fakultas Teknik, Universitas Jambi

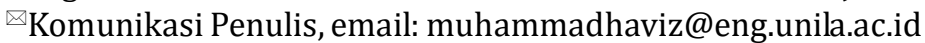 \\ DOI:http://dx.doi.org/10.23960/jtep-lv10i3.296-302
}

Naskah ini diterima pada 5 Mei 2021; revisi pada 12 Juni 2021; disetujui untuk dipublikasikan pada 17 Agustus 2021

\begin{abstract}
Increasing of ambient temperature due to global warming has a direct impact on increasing the room temperature. Heat from surrounding is transferred to building wall and room. By installing the Vertical Greenery System (VGS) on the building wall, it can be an alternative for heat absorber and eco-friendly indicator. The aims of this study are to determine the temperature that can be reduced by VGS type Green Façade (GF) and achieve the energy consumption reduction because of GF installation. GF is installed on the building wall, property of Mining Engineering Department, Sriwijaya University, to measure its temperature, then compare it with the temperature on control wall The results showed that the GF can reduce the room temperature up to $1,2^{\circ} \mathrm{C}$, compared to the control wall and the average is $0,3^{\circ} \mathrm{C}$. The decrease in average temperature causes a decrease in energy consumption due to the use of air conditioners by 1.56-1.92\%.
\end{abstract}

Keywords: global warming, green facade, thermal evaluation, vertical greenery system

\begin{abstract}
ABSTRAK
Peningkatan temperatur ambien akibat pemanasan global berdampak langsung terhadap peningkatan suhu ruangan pada sebuah bangunan. Hal ini terjadi karena adanya perpindahan panas dari lingkungan ke dinding bangunan dan dari dinding bangunan ke ruangan. Salah satu cara untuk menurunkan temperatur ruangan adalah dengan cara memasang Vertical Greenery System (VGS) atau taman vertikal pada dinding bangunan bagian luar. Penelitian ini bertujuan untuk mengetahui temperatur yang dapat direduksi oleh VGS tipe Green Façade (GF) serta mendapatkan nilai penurunan konsumsi energi akibat pemasangan GF. Green Façade dipasang pada salah satu dinding bangunan Jurusan Teknik Pertambangan Universitas Sriwijaya untuk diukur temperaturnya, kemudian dibandingkan dengan temperatur pada Control Wall (Dinding Biasa). Hasil penelitian menunjukkan VGS tipe GF dapat menurunkan temperatur ruangan hingga $1,2^{\circ} \mathrm{C}$ jika dibandingkan dengan Control Wall dan ratarata $0,3^{\circ} \mathrm{C}$. Penurunan temperatur ruangan rata-rata menyebabkan penurunan konsumsi energi sebesar $1,56-$ $1,92 \%$ akibat penggunaan pendingin ruangan.
\end{abstract}

Kata Kunci: evaluasi termal, global warming, green facade, taman vertikal

\section{PENDAHULUAN}

Pemanasan global (global warming) memberikan dampak yang dirasakan manusia baik dari skala global hingga skala kecil seperti bangunan. Pada bangunan, salah satu dampak dari pemanasan global dapat dirasakan dengan meningkatnya suhu di dalam ruangan. Peningkatan suhu di dalam ruangan yang tidak diimbangi dengan adanya media penyerap panas matahari pada dinding ataupun atap suatu bangunan akan mengakibatkan konsumsi energi yang tinggi, yaitu pada penggunaan pendingin ruangan (Perini dan Rosasco, 2013). 
Salah satu alternatif penghemat energi sekaligus pendingin ruangan pada suatu bangunan adalah Vertical Greenery System (VGS) (Coma et al., 2016). Menurut Wong et al. (2010a) dan Convertino et al. (2019), VGS merupakan bentuk penghijauan pada dinding bangunan dimana penggunaannya dengan menumbuhkan tanaman merambat pada dinding luar bangunan. Dengan konsep vertical garden, ruang tanam (space) bisa jauh lebih besar dibandingkan dengan taman konvensional, bahkan jumlah tanaman yang dapat ditanam bisa beberapa kali lipatnya, sehingga dapat menambah ruang hijau secara signifikan (Widiastuti et al., 2014).

VGS dapat menyerap panas dari lingkungan serta membuat kesan ramah lingkungan. VGS tipe Green Façade (GF) merupakan tipe dari VGS yang paling sederhana, ekonomis, mudah dalam pemasangan dan pemeliharaan. Green Façade (GF) merupakan salah satu tipe Vertical Greenery System yang paling sederhana dibandingkan tipe-tipe VGS lainnya. Green Façade dapat tumbuh tanpa menggunakan banyak media tumbuh (tanah), karena menggunakan tanaman rambat (Jim et al., 2011). Tanaman rambat dapat langsung tumbuh di dinding bangunan hanya dengan menggunakan kawat atau baja ringan (Widiastuti etal., 2020). Keuntungan lainnya dari penggunaan Green Façade adalah efek pendinginan karena proses evapotranspirasi dari tanaman (Blanco et al., 2017).

Menurut Ottele dan Perini (2017), Green Façade (GF) bukanlah tipe VGS yang paling baik dalam menyerap panas, karena hanya mengandalkan rambatan dari tanamannya. Akan tetapi GF merupakan tipe taman vertikal yang mudah ditanam dan dipelihara. Tujuan dari penelitian ini adalah untuk mengetahui temperatur yang dapat direduksi dari instalasi taman vertikal tipe Green Facade, serta penurunan konsumsi energi pada air conditioner di dalam ruangan.

\section{BAHAN DAN METODE}

Penelitian ini bertempat di salah satu bangunan milik jurusan Teknik Pertambangan Universitas Sriwijaya, Palembang. Pengukuran dilakukan selama $3 \times 8$ jam kerja, yaitu pukul 08.00 sampai 16.00. Pada penelitian ini, pengukuran temperatur dilakukan setiap 1 jam sekali dengan menggunakan thermocouple Krisbow tipe KW06-278 pada permukaan dinding yang terinstal Green Façade (GF) dan Control Wall (CW) atau dinding pembanding. Skema pengukuran temperatur mengadopsi Wong et al (2010b) dan dilakukan pada titik-titik berikut : (1) dinding luar ruangan, (2) dinding dalam ruangan, (3) Ruangan, (4) Ambient, (5) Substrat (Tanaman). Sedangkan untuk pengukuran relative humidity dengan menggunakan Environment Analysis Meter Lutron LM-9000. Untuk pengukuran relative humidity dilakukan di luar (ambient) dan dalam ruangan bangunan. Rincian dari skema titik pengukuran dapat dilihat di Gambar 1.

Pada Gambar 1, titik pengukuran temperatur ambient (surrounding), ruangan, dinding luar dan dalam, substrat serta relative humidity Untuk control wall, pengukuran hanya tidak dilakukan pada bagian substrat atau tanaman, yang berada di daun paling luar dan dekat dengan tanah tempat tumbuhnya. Sedangkan pengukuran pada Control Wall, sama seperti dinding yang terinstal GF, tanpa pengukuran temperatur pada substrat.

Pengukuran dilakukan di beberapa titik pada bagian luar dan dalam bangunan. Temperatur dinding merupakan temperatur dari dinding yang telah dipasang taman vertikal. Temperatur ambien merupakan temperatur dari lingkungan. Temperatur substrat merupakan temperatur dari tanaman, dan temperatur control wall merupakan temperatur dari dinding control. Kemudian untuk bagian dalam bangunan, Temperatur Ruangan 1 adalah temperatur ruangan yang titik ukurnya 1 meter di belakang dinding yang telah dipasang taman vertikal, sedangkan Temperatur Ruangan 2 adalah temperatur ruangan yang titik ukurnya 1 meter di belakang control wall.

Bahan-bahan yang digunakan antara lain : baja ringan, pipa pvc, valve, pot plastik, tanah sebagai media tanam dan Vernonia elliptica atau biasa dikenal dengan nama tanaman Lee Kwan Yew. Penggunaan Vernonia elliptica sebagai tanaman di konsep Green Façade ini dikarenakan tanaman ini mudah didapat, pemeliharaannya cenderung mudah dan dapat tumbuh dengan cepat. 


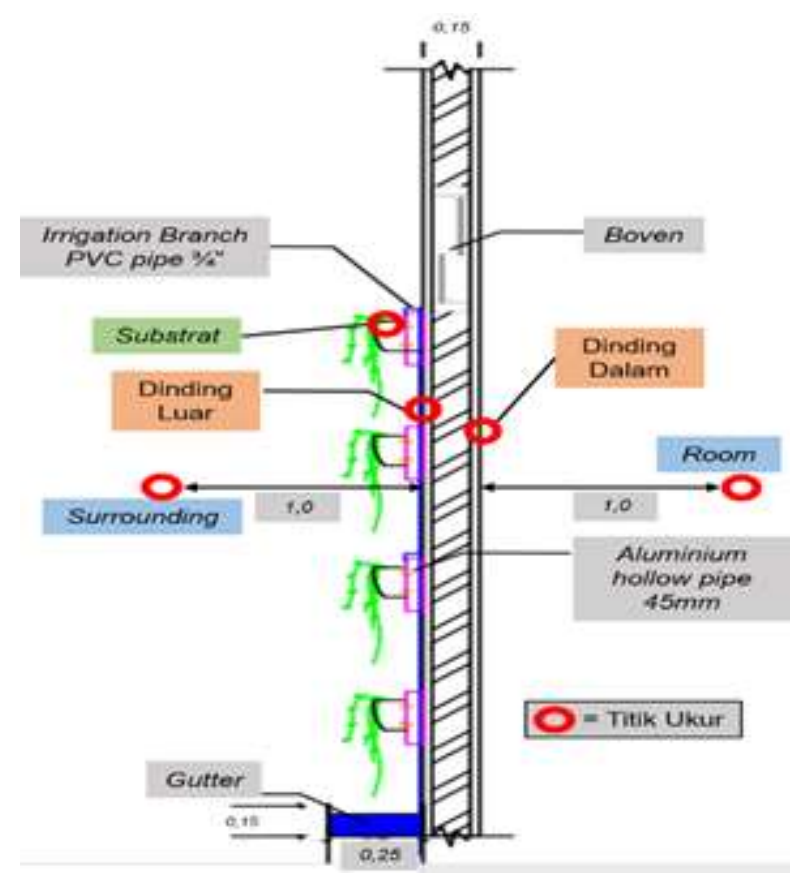

Gambar 1. Skema Pengukuran Temperatur dan RH Setelah Instalasi GF

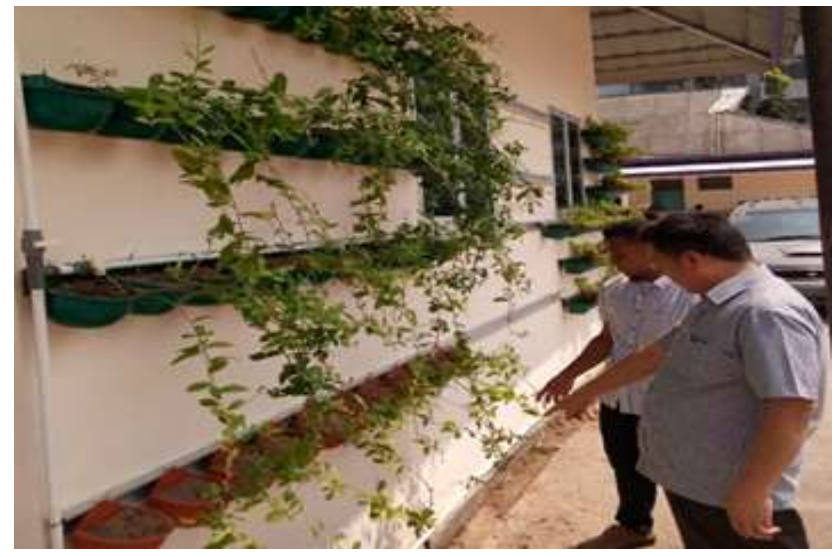

Gambar 2. Taman Vertikal Tipe GF

\section{HASIL DAN PEMBAHASAN}

\subsection{Desain Green Façade (GF)}

Taman vertikal tipe GF ini dipasang pada dinding dengan lebar 2,26 meter dan tinggi 2,5 meter. Terdapat sistem pengairan pada taman vertikal ini yang berupa pipa yang mensuplai air untuk 2 baris taman vertikal. Sedangkan untuk control wall sendiri berukuran $2,69 \times 2,5$ meter dikurang jendela ukuran $1 \times 1$ meter. Desain dari taman vertikal tipe GF beserta control walll dapat dilihat pada Gambar 3. Pada taman vertikal ini terdapat sekitar 32 pot yang berisi media tumbuh bagi tanaman rambat, dimana satu barisnya terdapat 8 pot dan ada 4 baris pada dinding tersebut.

\subsection{Pengukuran Temperatur dan Relative Humidity Rata-rata \\ 3.2.1. Bagian Luar Bangunan}

Tabel 1 menunjukkan nilai rata-rata temperature dan relative humidity dari tiga hari waktu pemngambilan data pada bagian luar bangunan. Pada Gambar 4 terdapat grafik perbandingan temperatur rata-rata pada dinding luar bangunan dan control wall. Perbedaan temperatur paling besar antara dinding yang telah dipasang GF dan control wall terjadi pada pukul 10.00 dan 11.00 , dimana perbedaan temperaturnya adalah $2,4^{\circ} \mathrm{C}$. Sedangkan untuk perbedaan temperatur paling kecil terjadi pada pukul 13.00 , yaitu $0,7^{\circ} \mathrm{C}$. 


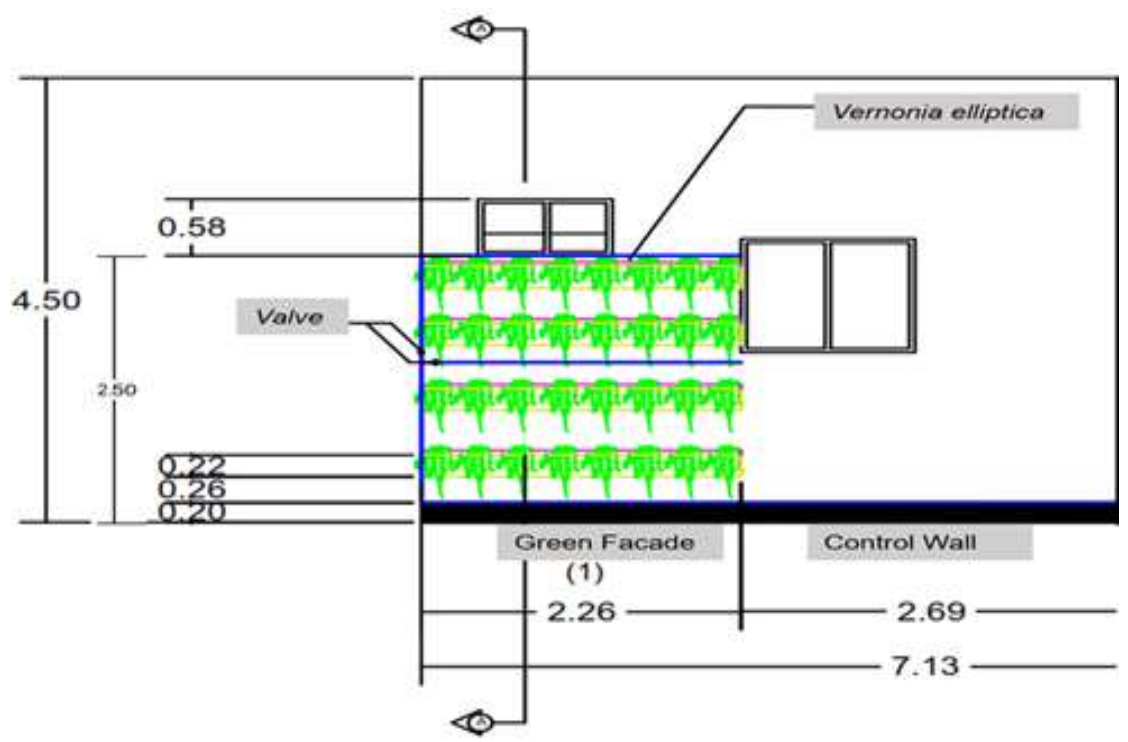

Gambar 3. Desain Taman Vertikal Dalam Satuan Meter

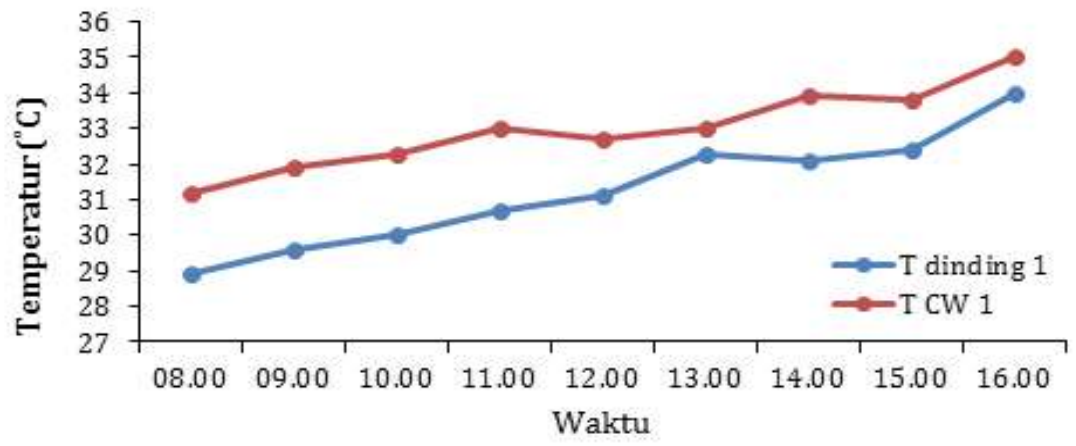

Gambar 4. Grafik Perbandingan Temperatur pada Dinding 1 dan Control Wall

Tabel 1. Temperatur dan RH pada Hari Rata-rata pada Bagian Luar Bangunan

\begin{tabular}{cccccc}
\hline \multirow{2}{*}{ Waktu } & $\begin{array}{c}\text { Temperatur } \\
\text { Ambien }\end{array}$ & $\begin{array}{c}\text { Temperatur } \\
\text { Dinding }\end{array}$ & $\begin{array}{c}\text { Temperatur } \\
\text { Substrat }\end{array}$ & $\begin{array}{c}\text { Temperatur } \\
\text { Control Wall }\end{array}$ & RH \\
\cline { 2 - 6 } & ${ }^{\circ} \mathbf{C}$ & ${ }^{\circ} \mathbf{C}$ & ${ }^{\circ} \mathbf{C}$ & ${ }^{\circ} \mathbf{C}$ & \% \\
\hline 08.00 & 30,8 & 28,9 & 31,4 & 31,2 & 57,6 \\
09.00 & 31,2 & 29,6 & 31,8 & 31,9 & 59,4 \\
10.00 & 31,5 & 30,0 & 33,1 & 32,3 & 60,6 \\
11.00 & 32,9 & 30,7 & 33,4 & 33,0 & 59,6 \\
12.00 & 31,7 & 31,1 & 32,3 & 32,7 & 61,2 \\
13.00 & 34,6 & 32,3 & 34,0 & 33,0 & 49,4 \\
14.00 & 35,5 & 32,1 & 35,5 & 33,9 & 49,6 \\
15.00 & 33,1 & 32,4 & 33,7 & 33,8 & 52,6 \\
16.00 & 33,3 & 34,0 & 34,1 & 35,0 & 53,2 \\
\hline
\end{tabular}

\subsubsection{Bagian Dalam Bangunan}

Tabel 2 menunjukkan nilai rata-rata temperatur dan relative humidity dari tiga hari waktu pengambilan data pada bagian dalam bangunan. Temperatur ruangan 1 merupakan temperatur dari ruangan yang berjarak 1 meter dari dinding yang telah dipasang GF. Sedangkan temperatur ruangan 2 merupakan temperatur dari ruangan yang berjarak 1 meter dari control wall. Kemudian, temperatur dinding 2 merupakan temperatur dari dinding bagian dalam yang telah terpasang GF pada luar bangunan, sedangkan temperatur control wall 2 merupakan temperatur dari dinding bagian dalam control wall. Adapun untuk nilai rata-rata perbedaan temperaturnya adalah $1,8^{\circ} \mathrm{C}$ 
Pada Gambar 5 terdapat grafik perbandingan temperatur rata-rata pada dinding 2 dan control wall 2. Dari Gambar 5 dapat dilihat, perbedaan temperatur paling besar antara dinding 2 dan control wall 2 terjadi pada pukul 15.00 dimana perbedaan temperaturnya adalah $1,5^{\circ} \mathrm{C}$. Sedangkan untuk perbedaan temperatur paling kecil terjadi pada pukul 10.00 , yaitu $0,2^{\circ} \mathrm{C}$. Adapun untuk nilai rata-rata perbedaan temperaturnya adalah $0,6^{\circ} \mathrm{C}$.
Pada Gambar 6 terdapat grafik perbandingan temperatur rata-rata pada ruangan 1 dan ruangan 2. Dari Gambar 6 dapat dilihat, perbedaan temperatur paling besar antara ruangan 1 dan ruangan 2 terjadi pada pukul 15.00 dimana perbedaan temperaturnya adalah $1,2^{\circ} \mathrm{C}$. Sedangkan untuk perbedaan temperatur paling kecil terjadi pada pukul 11.00 , yaitu $0,0^{\circ} \mathrm{C}$. Adapun untuk nilai rata-rata perbedaan temperaturnya adalah $0,3^{\circ} \mathrm{C}$.

Tabel 2. Temperatur dan RH pada Rata-rata pada Bagian dalam Bangunan

\begin{tabular}{cccccc}
\hline \multirow{2}{*}{ Waktu } & $\begin{array}{c}\text { Temperatur } \\
\text { Ruangan 1 }\end{array}$ & $\begin{array}{c}\text { Temperatur } \\
\text { Ruangan 2 }\end{array}$ & $\begin{array}{c}\text { Temperatur } \\
\text { Dinding }\end{array}$ & $\begin{array}{c}\text { Temperatur } \\
\text { Control Wall }\end{array}$ & RH \\
\cline { 2 - 6 } & ${ }^{\circ} \mathbf{C}$ & ${ }^{\circ} \mathbf{C}$ & ${ }^{\circ} \mathbf{C}$ & ${ }^{\circ} \mathbf{C}$ & $\mathbf{\%}$ \\
\hline 08.00 & 28,1 & 28,3 & 27,7 & 28,6 & 61,7 \\
09.00 & 28,6 & 28,7 & 28,2 & 28,8 & 64,5 \\
10.00 & 29,0 & 29,2 & 28,9 & 29,1 & 66,9 \\
11.00 & 30,5 & 30,5 & 30,0 & 30,3 & 54,1 \\
12.00 & 30,4 & 30,5 & 30,0 & 30,3 & 59,3 \\
13.00 & 30,4 & 30,6 & 30,1 & 30,6 & 54,4 \\
14.00 & 32,0 & 32,3 & 31,3 & 32,0 & 49,8 \\
15.00 & 30,5 & 31,7 & 30,0 & 31,5 & 55,4 \\
16.00 & 31,8 & 31,9 & 31,3 & 31,7 & 56,5 \\
\hline
\end{tabular}

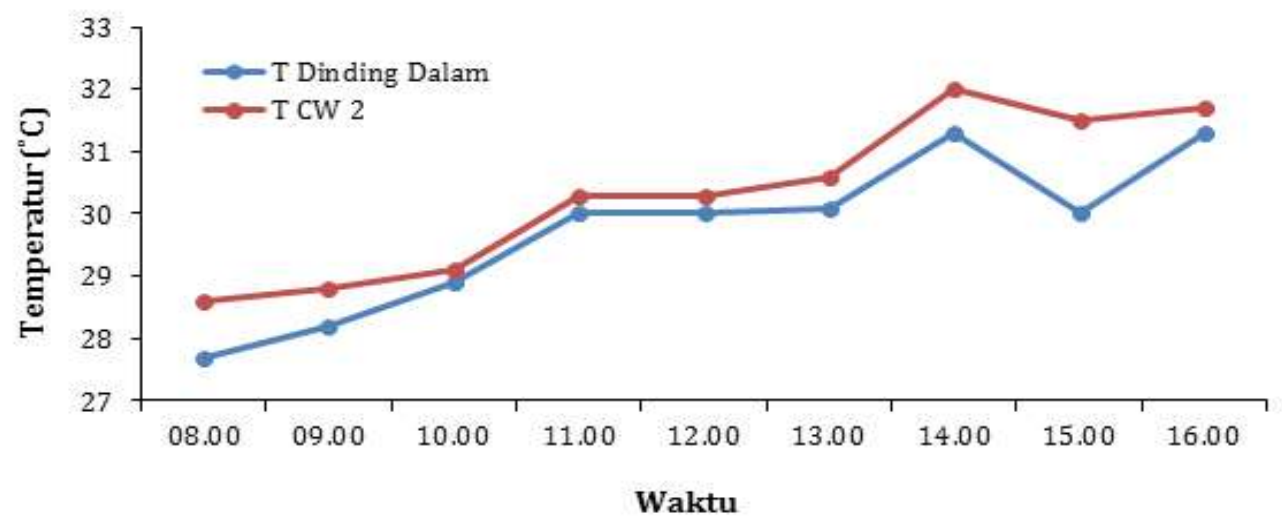

Gambar 5. Grafik Perbandingan Temperatur pada Dinding Dalam dan Control Wall 2

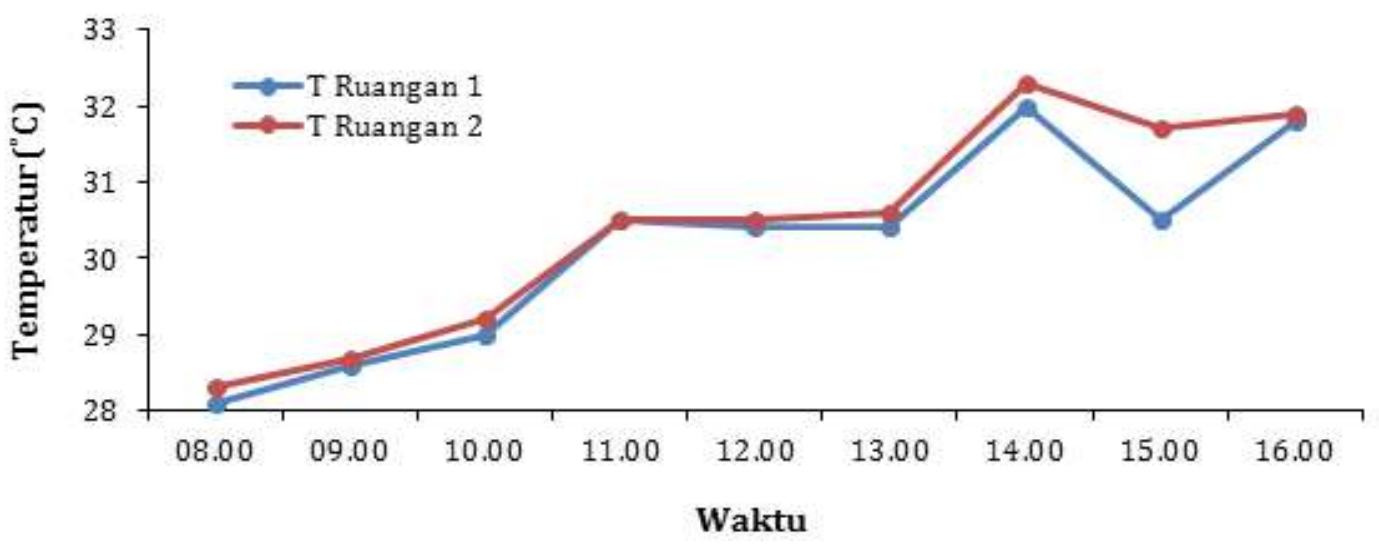

Gambar 6. Grafik Perbandingan Temperatur Ruangan 1 dan Ruangan 2 


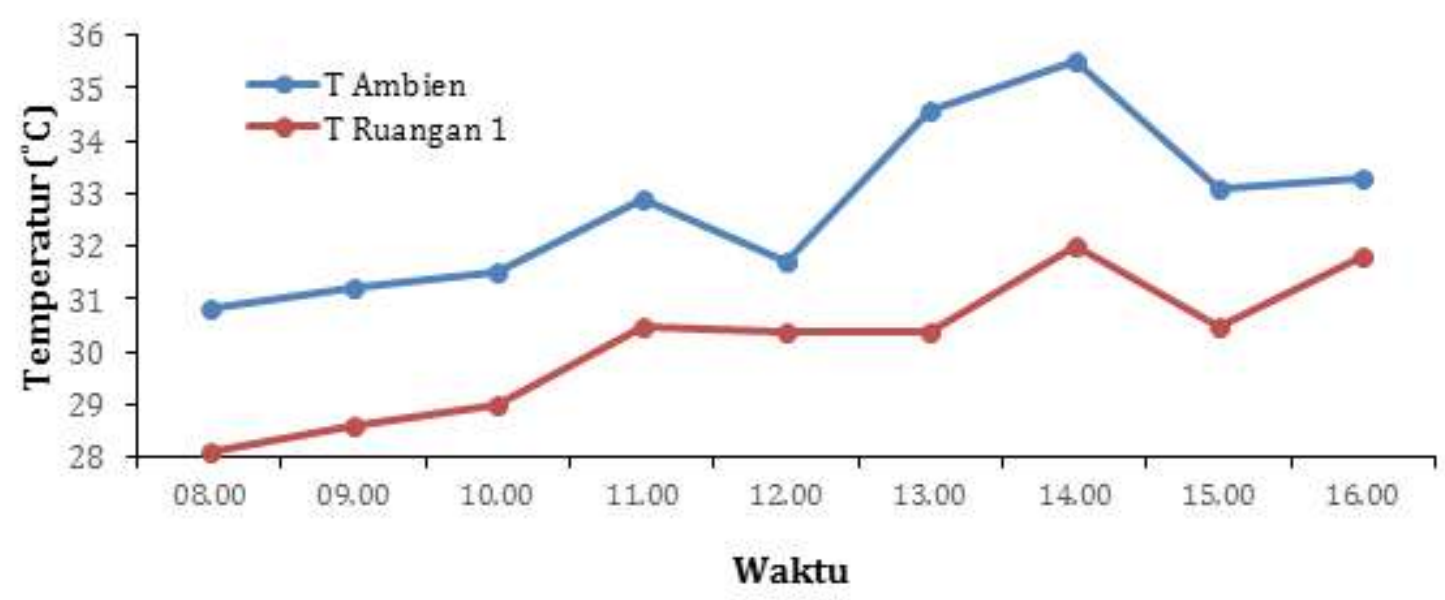

Gambar 7. Grafik Perbandingan Temperatur Ambien dan Ruangan

Pemasangan VGS pada dinding bangunan dapat menurunkan temperatur yang berasal dari panas yang ditransfer oleh lingkungan terhadap ruangan, hal ini bisa dilihat dari Gambar 7, dimana VGS dapat menurunkan temperatur paling besar $4,2^{\circ} \mathrm{C}$ yang terjadi pada pukul 13.00 . Sedangkan untuk perbedaan temperatur paling kecil terjadi pada pukul 16.00 , yaitu $1,5^{\circ} \mathrm{C}$. Adapun untuk nilai rata-rata perbedaan temperaturnya adalah $2,6^{\circ} \mathrm{C}$.

\subsection{Penurunan Konsumsi Energi}

VGS dapat membantu menurunkan konsumsi energi pada penggunan air conditioner pada saat cuaca panas, dan dapat menjadi insulator panas pada saat cuaca dingin (Cameron et al., 2014). Menurut Ge et al. (2013) penurunan suhu $1^{\circ} \mathrm{C}$ dari ruangan akan menurunkan konsumsi energi sekitar 5,2-6,2\%. Pada penelitian ini didapatkan perbedaan temperatur paling besar sebesar $1,2^{\circ} \mathrm{C}$, yang berarti dapat menurunkan konsumsi energi maksimal sekitar 6,2-7,44\%. Sedangkan untuk penurunan temperatur rata-rata yang didaptakan adalah $0,3^{\circ} \mathrm{C}$ atau setara dengan penurunan konsumsi energi sekitar 1,56-1,92\%.

\section{KESIMPULAN}

Pada penelitian ini dapat disimpulkan Vertical Greenery System tipe Green Façade dapat membantu menurunkan temperatur ruangan dari sebuah bangunan, dimana perbedaan temperatur paling besar pada ruangan adalah $1,2^{\circ} \mathrm{C}$. Secara rata-rata, temperatur ruangan mengalami penurunan sekitar $0,3^{\circ} \mathrm{C}$ selama jam kerja (8 jam). Jika dibandingkan dengan dinding yang permukaannya tidak dipasang Green Façade, instalasi Green Façade pada permukaan dinding bangunan dapat dikategorikan baik, karena dapat menurunkan konsumsi energi ratarata akibat penggunaan air conditioner sebesar $1,56-1,92 \%$.

\section{DAFTAR PUSTAKA}

Blanco, I., Schettini, E., Scarascia Mugnozza, G., Campiotti, C. A., Giagnacovo, G., dan Vox, G. 2017. Vegetation as a passive system for enhancing building climate control. Acta Horticulturae, 1170: 555-562.

Cameron, R. W., Taylor, J. E., dan Emmett, M. R. 2014. What's 'cool' in the world of green façades? How plant choice influences the cooling properties of green walls. Building and Environment, 73: 198-207.

Coma, J., Pérez, G., de Gracia, A., Burés, S., Urrestarazu, M., dan Cabeza, L. F. 2017. Vertical greenery systems for energy savings in buildings: A comparative study between green walls and green facades. Building and Environment, 111: 228-237.

Convertino, F., Vox, G., dan Schettini, E. 2019. Convective heat transfer in green façade system. Biosystems Engineering, 188: 6781.

Jim, C. Y., dan He, H. 2011. Estimating heat flux transmission of vertical greenery 
ecosystem. Ecological Engineering, 37(8): 1112-1122.

Ge, F., Guo, X., Liu, H., Wang, J., dan Lu, C. 2013. Energy performance of air cooling systems considering indoor temperature and relative humidity in different climate zones in China. Energy and Buildings, 64: 145-153.

Ottele, M., dan Perini, K. 2017. Comparative experimental approach to investigate the thermal behaviour of vertical greened façades of buildings. Ecological Engineering, 108: 152-161.

Perini, K., dan Rosasco, P. 2013. Cost-benefit analysis for green façades and living wall systems. Building and Environment, 70: 110-121.

Widiastuti, R., Prianto, E., dan Budi, W.S. 2014. Evaluasi Termal Dinding Bangunan dengan Vertikal Garden. Jurnal Penelitian dan Pengabdian kepada Masyarakat UNSIQ, 1(1): 1-12.

Widiastuti, R., Zaini, J., dan Caesarendra, W. 2020. Field measurement on the model of green facade systems and its effect to building indoor thermal comfort Measurement, 166: 108212.

Wong, N. H., Tan, A. Y. K., Tan, P. Y., Chiang, K., dan Wong, N. C. 2010a. Acoustics evaluation of vertical greenery systems for building walls. Building and Environment, 45(2): 411-420.

Wong, N.H., Tan, A.Y.K., Chen, Y., Sekar, K., Tan, P.Y., Chan, D., Chiang, K., dan Wong, N.C. 2010b. Thermal evaluation of vertical greenery systems for building walls. Building and Environment, 45(3): 663672. 